\title{
Juventude, Criatividade e Agência Política
}

Ricardo Campos*

Alix Sarrouy ${ }^{* *}$

\section{Resumo}

Este artigo tem por base um projeto em curso em Portugal (20192021) que visa refletir sobre as dimensões menos visíveis da participação dos jovens na vida pública contemporânea, explorando o que designamos por "Artes da cidadania". Este conceito remete para territórios não-institucionais de construção da cidadania e de participação na esfera política que recorrem a dinâmicas criativas diversas. Falamos do uso do corpo, das ruas e de outros recursos, para a construção de linguagens e conteúdos estéticos (sonoros, performativos, visuais, digitais, etc.) no âmbito da participação política e do exercício da cidadania. Deste modo, procuramos entender como a agência política está associada à agência criativa na juventude, uma articulação que tem sido amplamente estudada e debatida no âmbito dos estudos juvenis. Importa atualizar essa reflexão num período histórico que tem sido marcado por uma crescente presença e mobilização dos jovens em prol de diversas causas.

Palavras-chave: Participação política. Ativismo. Juventude. Criatividade. Artes.

* CICSNova (Nova FCSH). E-mail: rmocampos@yahoo.com.br

** CICSNova (Nova FCSH). E-mail: alixsarrouy@fcsh.unl.pt 


\section{Youth, Creativity and Political Agency}

\section{Abstract}

This article is based on an ongoing project in Portugal (2019-2021) that aims to reflect on the less visible dimensions of young people's participation in contemporary public life, exploring what we call "Arts of citizenship". This concept refers to non-institutional territories for the construction of citizenship and political participation that resort to diverse creative dynamics. We speak of the use of the body, of the streets and of other resources, for the construction of aesthetic languages and contents (sounds, performances, visual artefacts, digital contents, etc.) within the scope of political participation and the exercise of citizenship. In this way, we seek to understand how the political agency is associated with the creative agency in youth, an articulation that has been widely studied and debated in the scope of youth studies. It is important to update this reflection, in a historical period that has been marked by a growing presence and mobilization of young people in favor of various causes.

Keywords: Political participation. Activism. Youth. Creativity. Arts.

\section{Juventud, Creatividad y Agencia Política}

\section{Resumen}

Este artículo se basa en un proyecto en curso en Portugal (2019-2021) que tiene como objetivo reflexionar sobre las dimensiones menos visibles de la participación de los jóvenes en la vida pública contemporánea, explorando lo que llamamos "Artes de la ciudadanía". Este concepto se refiere a territorios no institucionales para la construcción de ciudadanía y participación en el ámbito político que recurren a dinámicas creativas diversas. Hablamos del uso del cuerpo, las calles y otros recursos, para la construcción de lenguajes y contenidos estéticos (sonido, performance, visual, digital, etc.) en el ámbito de la participación política y el ejercicio de la ciudadanía. De esta manera, buscamos entender cómo la agencia política se asocia con la agencia creativa en la juventud, una articulación que ha sido ampliamente estudiada y 
debatida en el ámbito de los estudios de la juventud. Es importante actualizar esta reflexión, en un período histórico que ha estado marcado por una creciente presencia y movilización de los jóvenes en favor de diversas causas.

Palabras clave: Participación política. Activismo. Juventud. Creatividad. Artes.

Este artigo parte de um convite que nos foi dirigido pelos organizadores do dossiê para refletirmos sobre o trabalho que temos desenvolvido no âmbito de um projeto atualmente em curso em Portugal. 0 projeto ArtCitizenship ${ }^{1}$ procura olhar para dimensões menos visíveis da participação dos jovens na vida pública contemporânea, explorando o que designamos por "Artes da cidadania". São pesquisados territórios não-institucionais de construção da cidadania e de participação na esfera política que recorrem a dinâmicas criativas diversas. Deste modo, procuramos entender como a agência política está associada à agência criativa na juventude. Esta é uma área onde, de fato, os jovens têm sido reconhecidos ao longo de décadas como especialmente prolíficos (Farthing, 2010; Lack, 2017).

Sabemos que a invenção da juventude enquanto sujeito contemporâneo está fortemente associada a uma dimensão lúdica, hedonista e consumista (Pais, 1993; Campos, 2010; Feixa, 2006). No entanto, a dimensão política está sempre latente na representação social e histórica desse grupo socio-etário. Há toda uma memória histórica marcada pelo Maio de 68, pelo movimento hippie, pelo ativismo Okupa e alter-globalização, ou, mais recentemente, pelos famigerados black-bloc. Falamos de movimentos sociais que, de uma forma ou de outra, questionaram e desafia- 
ram o status quo e as normas sociais dominantes, utilizando um conjunto de reportórios políticos e recursos estéticos para marcarem presença na esfera pública e defenderem certas causas. A juventude dificilmente escapa a esta imagem da rebeldia que parte de um lugar de subalternidade (Boyd \& Mitchell, 2012).

A criatividade associada à produção cultural e artística, à mobilização e ao protesto, mas também à promoção de certas causas sociais, tem sido apanágio de diferentes gerações de jovens, pelo menos desde meados do século passado. Por um lado, a inventividade colocada a serviço do protesto e da mobilização é algo que está muito presente nos movimentos anteriormente mencionados, bem como nos chamados novíssimos movimentos sociais (Feixa, Pereira e Juris, 2009). A música, o uso do corpo e da estética, as tácticas e performances de protesto são elementos distintivos. Por outro lado, também encontramos correntes e movimentos artísticos e culturais cuja componente política é marcante, confundindo-se o fito estético e lúdico com o ideológico. Para além do movimento hippie já referido, o punk e o hip-hop são outros bons exemplos. Mais recentemente tivemos diversos exemplos da criatividade colocada a serviço de novas formas de protesto, mobilização e confronto com o poder. Podemos invocar a este propósito exemplos espalhados pelo mundo fora em que o protesto juvenil assumiu especial protagonismo (Feixa e Nofre, 2013; Simões e Campos, 2020). As revoltas da Primavera Árabe (2010), o movimento Occupy (2011), a ocupação de escolas no Brasil (2016), os protestos de Hong-Kong ou do Chile (2019) estão entre os mais mediáticos. Sendo claramente diferentes dos movimentos sociais surgidos nas décadas de 60 e 70 do século passado, revelam, no entanto, muitas similaridades, entre elas o fato de procurarem a transformação social e de colocarem a expressão estética e a criatividade como elementos fundamentais da sua ação.

Os diversos exemplos que aqui trouxemos parecem contradizer a visão algo pessimista que, entretanto, se foi instalando e cristalizando, muito à força dos opinion makers e dos media mains- 
tream, que reverberam a imagem do jovem apático e desinteressado pela política. Não sendo completamente desprovida de sentido, essa imagem peca por ser claramente insuficiente, na medida em que não apenas parte de falsos pressupostos, como revela alguma miopia analítica. Teremos oportunidade de retornar a esse assunto no decorrer do artigo. Ainda assim, importa aqui salientar dois pontos. Em primeiro lugar, que determinadas circunstâncias sociais, econômicas e políticas despoletam uma vigorosa dinâmica de participação dos jovens na esfera pública, como ficou demonstrado pelos exemplos acima citados. Em segundo lugar, que a dimensão da cidadania e da participação política dos jovens é de índole difusa, horizontal, abrangente e ambivalente, de alguma forma colidindo com a esfera da política oficial, fabricada de acordo com um modelo adultocêntrico.

\section{Entre 0 jovem apático e 0 ativista rebelde}

Todos os dados parecem apontar para o fato de, nos países ocidentais/do norte global, existir um fosso crescente entre o sistema político e os mais jovens (Dahlgren, 2009; Moral, 2011; Benedecto, 2011, 2013; Menezes, 2011; Garcia-Albacete, 2014). Para esse fato há variadas explicações, que podem ser de ordem mais sistêmica ou de índole mais conjuntural. Para Moral (2011), o desapego político dos jovens pode ser explicado tendo em consideração quatro tipos de "efeitos". Em primeiro lugar, existe o efeito de idade, que aponta para o fato de os jovens, de uma forma geral, se interessarem menos pela política. 0 mesmo nos indica Garcia-Alabacete (2014) a partir de uma análise dos dados relativos à Europa, que indicam que a participação na política institucional é geralmente mais baixa nos jovens em comparação com os adultos. Ou seja, há um fator associado aos ciclos de vida que afeta o comportamento político. A passagem para a idade adulta comporta uma inversão da tendência, com uma tendência para o aumento da participação institucional e 
um decréscimo na participação não-institucional. Deste modo, uma das dimensões que está fortemente implicada no comportamento político é precisamente a que remete para os modos de transição para a idade adulta, sendo que este processo pode influenciar decisivamente a participação.

Em segundo lugar, existe o "efeito geração", que parte da ideia de que existe uma relação entre o contexto histórico e a socialização e agência política dos indivíduos. Neste sentido, as gerações seriam marcadas de forma distinta na sua relação com as instituições políticas e os seus atores. Ou seja, o contexto de transição complexa e não-linear que caracteriza grande parte dos países ditos ocidentais, com a aquisição tardia (e precária $^{2}$ ) de alguns atributos da condição adulta, tem implicações no comportamento político e pode eventualmente explicar um incremento mais tardio da participação política (Moral, 2011; Benedicto, 2011; Garcia-Albacete, 2014). Em terceiro lugar, o "efeito período", que remete para a importância das conjunturas e do contexto histórico, existindo períodos que podem favorecer ou contrariar a mobilização e participação políticas. A título de exemplo, podemos referir o caso da crise financeira e das consequentes políticas de austeridade que afetaram um conjunto de países europeus no início da década de 2010, dando origem a diversos fenômenos de mobilização política, nomeadamente entre os mais jovens (Carmo e Simões, 2020; Feixa e Nofre, 2013; Sloam e Henn, 2019; Pickard e Bessant, 2018). 0 último efeito é o denominado "efeito integração", que remete para uma associação entre a participação política e a integração na comunidade, sendo que uma maior integração corresponderá a uma maior participação. Claramente este efeito está articulado com o efeito idade, na medida em que a probabilidade de integração social aumenta com a idade e a transição para o estado adulto. 
Particularmente, desde o início das pesquisas sobre a juventude que a problemática da participação política não-convencional tem sido tratada. De acordo com Pitti (2018), podemos identificar três fases de pesquisa que fazem o retrato da juventude enquanto agentes de política não-convencional. A primeira fase, que se situa nos anos 60-70, dava conta de uma juventude fortemente participativa e mobilizada, envolvida em protestos que visavam a mudança social (exemplo do Maio de 68, dos movimentos de contrapoder nos EUA, da oposição à guerra do Vietnã, etc.). A fase que se segue abrange as duas décadas seguintes, e revela uma paulatina quebra de confiança no sistema político e um abandono da participação política dos jovens, destacando, todavia, o surgimento de novos fenômenos de participação política menos evidentes, associados por exemplo a estilos de vida subculturais (as formas de resistência simbólica, destacada pelos CCCS). Finalmente, o início do milênio dá origem a uma fase em que se destaca a individualização e fluidez da participação política dos jovens orientada para causas específicas (cause-oriented engagement), que acompanha um desinteresse pela política formal e os seus atores. A definição de participação política "não-convencional" pode assumir várias configurações, embora Pitti (2018) aponte para formas de participação com as seguintes características: (a) reportórios de ação inovadores; (b) valores heterodoxos; (c) não adesão às normas do sistema político vigente; (d) são formas de protesto.

Assim, de um modo geral, parece que os jovens estão mais propensos a agir politicamente fora da esfera institucional, situação que se deve, por um lado, aos condicionamentos sociais referidos e, por outro lado, àquilo que, numa leitura essencialista, remete para as peculiaridades desta fase de vida. Os jovens estariam assim mais disponíveis para a política não-convencional porque isto se inscreve mais diretamente num conjunto de traços psicossociais e culturais típico desta população: o fulgor, dinamismo, rebeldia, criatividade, ingenuidade, entre outras singularidades tradicionalmente atribuídas a este grupo etário. 
Assim, parte da literatura oferece-nos uma visão mais otimista da juventude, representada como sendo o motor de formas sofisticadas de fazer política na contemporaneidade (Bassoli e Lahusen 2015; Bennet 2009; Harris et al., 2010; Stolle e Hooghe 2011; Pickard e Bessant, 2018; Feixa e Nofre, 2013; Loader, Vromen e Xenos, 2014; Kennelly, 2011; Giroux, 2016). Este paradigma, que tende a ver os jovens como ativos e empenhados, contornando uma versão mais minimalista da participação centrada na política formal e no voto, optando por uma versão maximalista, que alarga o espectro do "político". Esse envolvimento dos jovens inclui políticas de identidade, consumo consciente ou ativismo comunitário que, muitas vezes, ficam à margem da política formal.

Segundo Beck (2001), os jovens vivem hoje numa realidade diferente da das gerações anteriores, não fazendo sentido avaliar o seu envolvimento político de acordo com os critérios que se aplicavam às gerações do passado. Daí que fale de novas "agendas", "esferas" e "formas de ação" políticas. Por um lado, a nova realidade em que os jovens vivem obriga a uma atualização das agendas políticas - associadas, por exemplo, a políticas da vida (life politics), o que leva a ações micropolíticas ou orientadas para causas específicas (sustentabilidade, igualdade, pobreza, etc.). Estas "novas agendas" têm duas características: em primeiro lugar, exigem ações intensivas e pessoais; em segundo lugar, transcendem as fronteiras nacionais sendo dificilmente geríveis a nível global. As velhas estruturas políticas não estão adaptadas a este contexto, que envolve matérias/problemas globais e lógicas de ação individualizadas e fluidas. As novas agendas juvenis surgem dessa nova realidade.

Por outro lado, deparamo-nos com uma nova realidade global, que corresponde a um enfraquecimento do poder do Estado-nação para dar resposta a um conjunto de questões, bem como a consciência de um conjunto de novos atores globais (como as grandes corporações econômicas). A ação política se desenrola então em novas "esferas", dirige-se cada vez mais a novos atores. 
Finalmente, encontramos "novas formas" de participação. Para os jovens delegar o poder de ação política nos governos e atores tradicionais faz pouco sentido, na medida em que não respondem a estas novas agendas. Daí que necessitem atualizar as suas formas de participação política, que podem incluir consumo consciente, ativismo digital, vídeoativismo, produção musical, etc. Os jovens tendem a colocar as preocupações globais numa matriz de ação individualizada, de acordo com uma máxima do think global, act local: "In short, many young people now live their politics, they do not vote for change; they do change" (Farthing, 2010, p. 189).

Com uma certa falência dos modelos tradicionais da ação política e o profundo desgaste da imagem das instituições e da classe política, surgem novas formas de conceber o campo político que não se reduzem ao período formal das eleições, mas abrangem o quotidiano e campos tão diversos como a intimidade, a ecologia, os estilos de vida, a sexualidade, etc. Estas tendências surgem no decurso de um conjunto de outros processos de natureza social. Alguns autores têm apontado para uma gradual fragmentação e individualização da ação política (Bennett e Segerberg, 2011; Kennely, 2011) e, simultaneamente, para uma maior porosidade entre as esferas pública e privada, com uma contaminação do político pelas esferas do lazer e do entretenimento (Street, Inthorn e Scott, 2013; Soep, 2014).

Em resumo, podemos afirmar que os estudos dedicados ao envolvimento político dos jovens têm destacado formas de participação política menos convencionais e mais minoritárias, que acontecem nas franjas da política formal, alargando a definição de político, da cidadania e da esfera pública. A sua ação ocorre geralmente no campo da micropolítica ou nos 'off the radar' acts of citizenship (Walsh e Black, 2018). 


\section{Crio, logo participo}

A dimensão da criatividade é algo central na forma como esse grupo socio-etário tem sido analisado por parte das ciências sociais. A criatividade é o motor para a inovação, para a construção de identidades sociais, para a formação de vínculos grupais e para a produção de um conjunto de bens simbólicos (Willis, 1990; Hebdige, 1976; Bennett, 2015). Esse é, todavia, um termo complexo e susceptível de diferentes leituras. A criatividade, como qualquer conceito polissêmico, varia imenso na sua interpretação, mas também, e sobretudo, no que dela resulta. A palavra criatividade é recente no nosso léxico. Surge nos Estados Unidos em meados do século XX (Folio, 2011, p. 38) em forma de neologismo para significar a capacidade de idealizar e de produzir novas coisas. Nos anos 1950 a criatividade era vista como uma capacidade, uma força, um talento. A área da psicologia foi das primeiras a interessar-se pelo seu estudo, pretendendo entender de onde surge e por quais mecanismos (Guilford, 1950). A criatividade é, desde cedo, conotada com a noção de "capital humano", sendo vista como uma capacidade aplicada à resolução de problemas e à inovação (LaChapelle, 1983, p. 132).

No final do século XX a palavra criatividade vai ser aplicada, também, a um nível mais macroestrutural e econômico, sendo um conceito fundamental para a afirmação de um modelo econômico neoliberal aplicado a um conjunto de dimensões da vida social: cidades, classes, clusters, turismo, empreendedorismo. De destacar um conjunto e autores de relevo que cunhou as noções de "cidade criativa" (Landry, 2012; Landry \& Bianchini, 1995), e de "classe criativa" (Florida, 2002). Estas abordagens têm sido também altamente criticadas por um conjunto de autores (Mould, 2015; Schacter, 2014), apontando a leitura enviesada, classista, elitista, instrumental e economicista de muitas utilizações deste termo, nomeadamente por parte do poder público. 
No entanto, aquilo que aqui nos importa não é tanto essa lógica utilitária e economicista da criatividade, mas antes outra dimensão. Interessa-nos focar a criatividade enquanto competência humana, aplicada em diferentes esferas da nossa vida coletiva. De uma forma geral, a criatividade está associada ao carácter inovador, muitas vezes disruptivo, de ideias que contribuem para a transformação (Paulus e Nijstad, 2003; Fischer e Vassen, 2011). Como refere White (2008, p. 46), a criatividade: "must affirm the unforeseeable and contingent, and consequently aspire to transcend the limits imposed by habits (even if momentarily) in order to disrupt the static and sedimented dimensions of human action".

A criatividade está, então, basicamente associada à ideia de mudança, mas também à improvisação e resolução de problemas, funcionando numa interface entre a dimensão racional e emocional. Pode, por isso, ser entendida como provocadora, nomeadamente para visões mais conservadoras, porque cria tensão face ao que já estava instituído, ao que garante a estabilidade (Hallam e Ingold, 2007, p. 119). Geralmente a criatividade é entendida como uma capacidade individual, tendo sido estudada basicamente neste âmbito. Mais recentemente tem sido prestada maior atenção aos fatores sociais e contextuais associados à criatividade. Como referem Fischer e Vassen (2011) há um conjunto de novas abordagens teóricas no campo da teoria cultural (envolvendo, por exemplo, os conceitos de intertextualidade, hibridismo ou participatory culture) que abre espaço para pensar a criatividade na sua vertente coletiva, o que permite que falemos de criatividade "de grupo" (Sawyer, 2003; Paulus e Nijstad), "coletiva” (Armstrong, 2002; Fischer e Vassen, 2011) ou também "distributed" (Sawyer e DeZutter, 2009). Todavia, ainda que haja uma maior atenção por parte das ciências sociais à natureza coletiva da criatividade, esta está geralmente circunscrita a contextos microssociais e grupais, com redes e fronteiras espaciais bem delimitadas. Esta situação pode, no entanto, ser questionada à luz de novas possibilidades técnicas, que complexificam a nossa relação com os outros e pos- 
sibilitam o surgimento de novas interações sociais de natureza desterritorializada. 0 surgimento da internet e, desde o início deste século, a rápida expansão desta rede e dos dispositivos de acesso à mesma (particularmente os móveis), veio alterar significativamente a forma como nos relacionamos com os outros, em diferentes esferas da vida coletiva (Castells, 2000, 2001). Esta condição de profunda interconexão desterritorializada tem implicações para a forma como a criatividade coletiva pode ser pensada, situação que tem sido, aliás, fortemente explorada por um conjunto de autores que tem trabalhado sobre o impacto da internet na cultura contemporânea. Noções como a de "inteligência coletiva” (Lévy, 2007), comunidades virtuais (Van Dijk, 1997; Recuero, 2004) ou cultura participativa (Jenkins, 2006; Soep, 2014; Burgess e Green, 2009) remetem para novas formas gregárias, para novas fórmulas de comunicação, de criação de sentido e de conteúdos que são geradas coletivamente e que dependem destes processos de criatividade de grupo.

A dimensão da criatividade também tem sido aplicada ao domínio da participação política, estando geralmente associada a modos de envolvimento na esfera pública de natureza não-institucional ou não-convencional. Por um lado, remetem para práticas de mobilização, expressão, reivindicação ou contenda política que utilizam formatos originais, inesperados e disruptivos. Por outro lado, também endereçam para os domínios da estética e da comunicação que, como sabemos, são fundamentais em política. E há todo um universo que se vem expandindo nesse domínio e que contrasta com a natureza rígida e pré-determinada da política institucional.

Essas formas de "participação criativa", como denomina Micheletti (2010), exploram uma nova atitude perante o mundo. A literatura tem dado conta dessa dinâmica, trabalhando a partir de conceitos como "creative democracy" (Katherine Hankins, 2017), "aesthetics of protest" (Buser, et al., 2013), "creative citizen" (Hargreaves e Hartley, 2016) ou "artivism" (Sandoval e 
Latorre, 2008), que revelam a importância da criatividade, quer para exercícios de micropolítica no quotidiano, quer para ações mais episódicas de contentious politics. A importância dessa dimensão para o exercício da cidadania e participação política é imensa.

Nesse âmbito, um dos termos que tem mais sido utilizado é o de artivismo, cunhado por Chela Sandoval e Gisela Latorre (2008, p. 82): "The term artivism is a hybrid neologism that signifies work created by individuals who see an organic relationship between art and activism". Apesar de ter surgido há pouco mais de uma década, esse termo procede de uma linhagem de práticas que não são propriamente novas. Podemos, por exemplo, referir todos os movimentos que combinaram arte e intenção política que o antecederam ao longo do séc. XX - Dadaísmo, Internacional Situacionismo, Fluxus, etc. (Di Giovanni, 2015; Delgado, 2013).É de notar a relação profunda entre artivismo e as práticas de ocupação do espaço público - bem como conceitos de performance e liminaridade que são usados para a sua compreensão -, como alguns autores notam (Di Giovanni, 2015; Mourão, 2015). Para além da estreita relação entre artivismo e os novos/novíssimos movimentos sociais, é igualmente de destacar como fator relevante para a crescente visibilidade de práticas artivistas, uma certa tendência atual da arte contemporânea de explorar o seu potencial político (Mourão, 2015).

No entanto, detectamos a mobilização dos recursos criativos num conjunto de outras atividades que não têm sido socialmente enquadradas no campo da arte que, como sabemos, é um termo carregado de normatividade.

\section{Jovens e cidadania criativa}

Após essas primeiras páginas podemos concluir que existe um imaginário social que reforça a ideia de uma juventude criativa, com práticas e ideias inovadoras, com capacidade para contornar 
uma certa normatividade e cristalização sociais. Daí que a mudança social seja regularmente atribuída à juventude, por aquilo que vai impondo enquanto mudança de hábitos e estilos de vida.

O conceito de cidadania, na medida em que é mais abrangente permite integrar diferentes esferas de agência política, é aquele que, a nosso ver, melhor pode servir para descrever o campo de agência política dos jovens. A cidadania é um conceito polissêmico, que envolve distintas interpretações que oscilam entre o estritamente jurídico-legal e abordagens bem mais amplas envolvendo questões de índole social e cultural. No entanto, a literatura acadêmica tem vindo a reforçar uma leitura mais abrangente do conceito: "Rather than merely focusing on citizenship as legal rights, there is now agreement that citizenship must also be defined as a social process through which individuals and social groups engage in claiming, expanding or losing rights" (Isin e Turner, 2002, p. 4).

No seu sentido mais estrito, o conceito de cidadania, quando aplicado aos jovens, tem um conjunto vasto de implicações. Desde logo porque os jovens até atingirem a maioridade estão privados de um conjunto de direitos e deveres típicos da cidadania, como no caso da capacidade de participação política por inteiro (possibilidade do exercício do voto). A cidadania é, por isso, um conceito hierárquico (Smith, 2015), exclusivista e homogeneizador (Menezes, 2011), na medida em que as crianças e jovens se veem impossibilitadas de aceder à cidadania plena por constrangimentos de ordem política, econômica e social. Como refere Machado Pais (2005, p. 57), esse é um conceito que marca linhas de pertença e, consequentemente, de exclusão:

Tradicionalmente, o conceito de cidadania estabelece fronteiras e margens entre sociedades e grupos. Uns são enquadrados (os "incluídos"), outros desenquadrados (os excluídos, os marginais). Mas as margens são definidas a partir do centro, isto é, de valores que são próprios de "nós" (os enquadrados) por contraposição a "eles" (os excluídos). 
Desse modo, a cidadania tem estado associada à ideia de transição e de aquisição de um conjunto de atributos (Benedicto, 2011). Logo, é, em grande medida, um projeto e um objetivo na formação dos jovens. 0 que explica a existência de uma série de instituições sociais que trabalham no sentido de formar o "bom cidadão", de acordo com um conjunto de normas sociais. Abordagens mais recentes propõem que a cidadania não seja pensada como um estado a ser alcançado com a maioridade (estado adulto), mas antes um processo social (de envolvimento com o mundo) (Hall, Coffey e Williamson, 1999; Harris, 2015). De acordo com Harris (2015, p. 84), cidadania juvenil (youth citizenship) corresponde a: "The ways young people operate and are recognized as competent social and civic actors”, em três áreas: Participação, Pertença e Reconhecimento. "Participation is about engagement in society and constructing a publicly minded self, belonging is about membership and social and civic bonds, and recognition is about having one's competencies and rights acknowledged." (Harris, 2015, p. 85).

Não basta hoje pensar na cidadania apenas enquanto um estatuto jurídico-legal, mas antes como um processo que tem em consideração a forma como os indivíduos se relacionam com uma comunidade política. Há, então, um alargamento da própria definição que decorre de transformações sociais que ocorreram historicamente e que colocam em causa alguns dos princípios da lógica de atribuição da cidadania por parte do Estado-nação, mas também de uma complexificação da estrutura social que exige novas formas de reconhecimento social e atribuição de direitos.

Pensar a cidadania não como um estatuto, mas antes como um processo, implica ter em consideração a dinâmica que envolve as lutas dos sujeitos num determinado campo político e, como sugere Isin (2017), uma abordagem performativa da cidadania. Os direitos e deveres da cidadania envolveram, historicamente, luta e negociação. A cidadania é praticada não apenas pelo exercício de determinados direitos, mas também pela reivindicação deles. De acordo com o autor, uma perspectiva performativa da 
cidadania como reivindicação de direitos cruzando múltiplos grupos sociais e comunidades políticas revela as suas possibilidades criativas e transformadoras. Nas palavras de Isin, a cidadania performativa

(...) enables researchers to study how people stage creative and transformative resistances and articulate claims against domination (e.g. oppression, repression, discrimination, inequality) and the injustices it precipitates. Their focus is not only on the exercise of rights and duties as they exist but also on claiming rights and duties yet to come as a result of social struggles. (Isin, 2017, p. 506).

O autor foca a sua atenção nas ações dos indivíduos, na forma como as pessoas criativamente performam a cidadania em vez de seguirem um guião. Esta dinâmica desempenha um papel importante na contestação e construção de cidadania e na atribuição de sentido aos direitos. É neste contexto que surgem os "atos de cidadania":

(...) those acts that transform forms (orientations, strategies, technologies) and modes (citizens, strangers, outsiders, aliens) of being political by bringing into being new actors as activist citizens (claimants of rights and responsibilities) through creating new sites and scales of struggle. (Isin, 2017, p. 506).

E como pode essa cidadania ser exercida criativamente por parte dos jovens? De diferentes formas a nosso ver. Desde logo no simples ato de criação, a partir do qual, como vimos, se questiona o instituído, se rompe o cristalizado, se produz inovação e propõe transformação social. E, neste caso, importa entender que apesar de a criatividade ser particularmente aplicada no campo da arte e da produção estética, cultural e científica, consideramos que esta é uma competência genérica humana. Como tal, interessa-nos pensar a criatividade na perspectiva do 
homem comum, aquela que é utilizada nas diferentes esferas do quotidiano, no sentido da "vernacular creativity" (Burguess, 2006) ou da "criatividade simbólica" (Willis, 1990). O conceito de criatividade simbólica empregue por Willis no âmbito do seu estudo das culturas juvenis é a este respeito muito relevante.

A dimensão da criatividade quotidiana, aplicada nas diferentes esferas do lazer, do lúdico, da sociabilidade ou produção cultural e simbólica é algo que tem sido particularmente escrutinado no âmbito dos jovens (Hebdige, 1976; Willis, 1990; Bennet, Campos, 2010; Bennett e Kahn-Harris, 2004; Feixa, 2006). A dimensão da produção estética, seja através da visualidade e do estilo (Feixa e Porzio, 2008; Campos, 2011b), seja através da criação de diversos conteúdos musicais, digitais, videográficos, etc. (Bennet, 2015; Guerra, 2018; Simões, 2010; Aderaldo e Raposo, 2016), tem estado fortemente associada à constituição das culturas e subculturas juvenis. Mas a criatividade também é aplicada na forma como o espaço é empregue, remetendo para novas fórmulas de apropriação do território que, em muitos sentidos, contradizem os usos pré-definidos e autorizados (Pais, 2005; Campos, 2011a; Feixa, 2003). Ora essas expressões podem ser consideradas, em muitos sentidos, como atos de cidadania, na medida em que envolvem uma afirmação ou luta por certos direitos. Direitos de expressão ou de uso da cidade, por exemplo. 


\section{JUVENTUDE, CRIATIVIDADE E AGÊNCIA POLITICA}

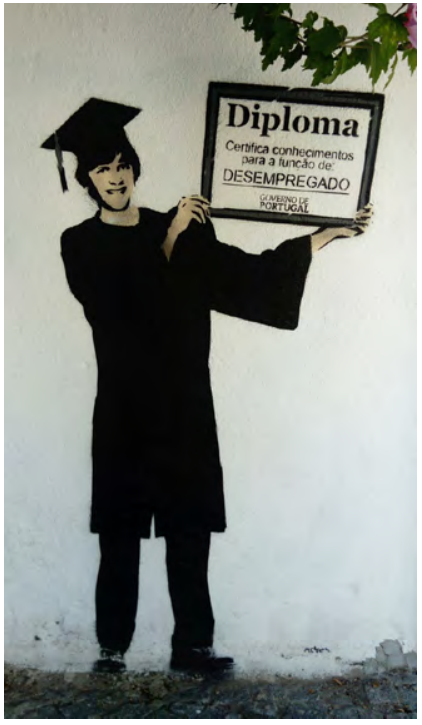

Fig. 1 - Stencil fazendo alusão ao desemprego juvenil (Covilhã, Portugal).

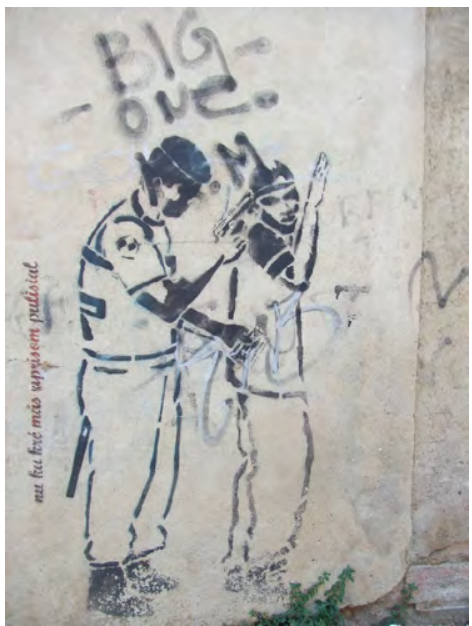

Fig. 2 - Stencil fazendo alusão à coerção e violência policial sobre os jovens (bairro da Cova da Moura, Amadora, Portugal). 


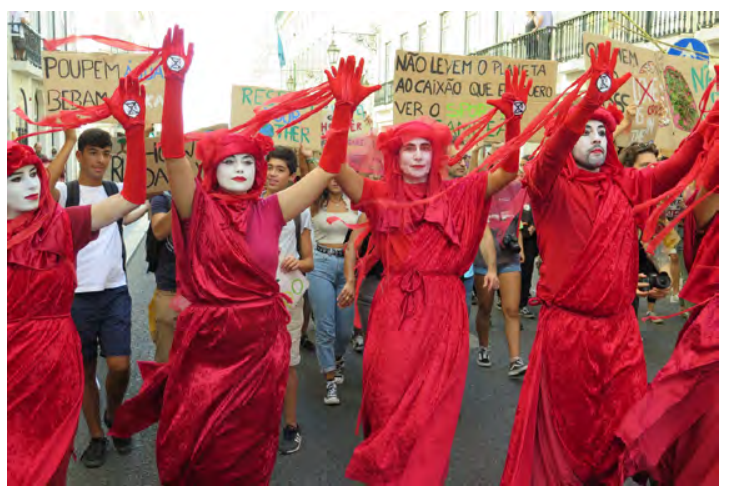

Fig. 3 - Greve climática juvenil, Extinction Rebellion Portugal (Lisboa).

Desse modo, grande parte da forma como a juventude se empenha em causas sociais, em movimentos alternativos de contestação ou resistência ao Estado e aos poderes dominantes, na constituição de políticas de identidade em torno do gênero, da etnia, etc., passa por processos criativos e pela produção e consumo de artefatos estéticos. Daí que haja uma extensa literatura que aponta precisamente para o papel político das DIY cultures (McKay, 1998; Hargreaves e Hartley, 2016) ou do ativismo cultural (Buser et al., 2013; Baumgarten, 2015) e, mais especificamente, em práticas como as do punk (Guerra, 2018), do rap (Campos, Nunes e Simões, 2016; Campos e Vaz, 2013; Raposo, REF), do graffiti e da street art (Campos, 2018a, 2018b; Zaimakis, 2015; Yanik, 2015), da performance (Juris, 2015; Vergara, 2015; Mourão, 2015) ou do vídeoativismo (Aderaldo, 2017). Neste contexto, e como refere Harris (2015, p. 87): “What we must grapple with now, however, is the enduring importance that the domains of culture and leisure have in the lives of the current generation, and their significance as a space of civic life and for the achievement of competencies and coherence". 


\section{Conclusão}

Este artigo surge no âmbito de uma reflexão teórica e conceptual ainda em curso que pretende fazer uma articulação entre os jovens, a criatividade e as formas contemporâneas de participação política. A relevância dessa questão é determinada, desde logo, por um discurso apoiado por dados científicos e que encontra eco na esfera pública, que diagnostica um problema. 0 problema identificado é o da crise do regime democrático que, em grande medida, é causa e consequência de um gradual descrédito dos atores e instituições e um crescente desapego dos cidadãos, particularmente dos mais jovens. Este diagnóstico justifica a produção de um discurso por parte do poder público e de ações que visam contrariar essas tendências, educando para a cidadania e procurando criar laços mais fortes entre os jovens e o sistema político.

Esta visão pessimista é contrariada por uma linha de pesquisa que recupera o papel dos jovens como sujeitos políticos relevantes, entendendo inclusive a sua ação como uma expressão de dinamismo e um indicador de saudabilidade do regime democrático. A sua postura, umas vezes apontada como apática, outras como apolítica, não deixa de ser profundamente política, na medida em que revela uma atitude perante as instituições e os seus atores que redunda, tantas vezes, em vias diversas para a participação. É no campo do exercício de uma cidadania expandida que podemos encontrar muitos desses casos. Contrariamente a uma visão minimalista da política e da cidadania, que tende a olhar para os cidadãos num papel passivo, de "espectadores que votam" (Walzer, 1995, p. 165, apud Menezes, 2011, p. 334), convém olhar o horizonte de forma mais alargada, procurando não apenas outras formas de compreender o político, mas também de o exercer. Daí que muitos jovens rappers da periferia da área metropolitana de Lisboa tenham sido pioneiros ao lançar as bases para a denúncia do racismo e da violência policial em Portugal, quando esta questão era praticamente ignorada 
pelos poderes públicos e instituições políticas (Fradique, 2003; Campos, Nunes e Simões, 2016). Também foram os jovens que se mobilizaram no recente período da crise financeira e econômica, utilizando as paredes para através do graffiti expressarem o seu descontentamento (Zaimakis, 2015; Campos, 2018b). De igual forma, as causas climáticas têm sido fortemente dinamizadas e ampliadas a partir da mobilização de jovens que seguem o exemplo de G. Thurnberg.

A criatividade surge de mãos dadas com esses processos de agência política que expandem o campo da política e anunciam novas "agendas", "esferas" e "formas de ação" (Beck, 2001). Em alguns casos os jovens estão mesmo na linha da frente, trazendo para a esfera pública novas questões e problemas ou inaugurando novos procedimentos. A criatividade entrevê-se nos processos coletivos que dão origem a formas emergentes de ativismo digital (Simões e Campos, 2020; Campos e Simões, 2018) e de cultura participativa (Jenkins, 2006; Soap, 2014), na forma como o território citadino é apropriado para ações de flash mob (Molnar, 2014) ou para a ação disruptiva dos pixadores da periferia das cidades brasileiras (Pereira, 2016). Nestes casos referidos, independentemente da ação ser conscientemente política ou não, fato é que se impõe como ação e discurso, exigindo que lhe prestemos atenção, deste modo conquistando um lugar na esfera pública. Há, por isso, uma cidadania inovadoramente participada (Pais, 2005, p. 57), "uma cidadania de novos direitos conquistados, cuja premência é justificada pelas circunstâncias ou necessidades mutáveis da vida".

\section{Ref erências}

Aderaldo, Guilhermo. “Territórios, mobilidades e estéticas insurgentes. Refletindo sobre práticas e representações coletivas de realizadores visuais nas metrópoles contemporâneas", Cadernos de Arte e Antropologia, Vol. 6, No 2 | -1, 2017, 31-48. 
Aderaldo, Guilhermo e Otávio Raposo. "Deslocando fronteiras, notas sobre intervenções estéticas, economia cultural e mobilidade juvenil em áreas periféricas de São Paulo e Lisboa", Horizontes Antropológicos, vol.22, n.45, 2016, pp.279-305.

Baumgarten, B. Culture and Activism across Borders. In B. Baumgarten, P. Daphi and P. Ullrich (eds.), Conceptualizing Culture in Social Movement Research. Basingstoke: Palgrave, 2015, 91-112.

Beck, U. Freedom's Children. In: U. Beck and E. Beck-Gensheim (eds.), Individualisation. London: Sage, 2001, 156-171.

Benedicto, J. The political cultures of young people: an uncertain and unstable combinatorial logic. Journal of Youth Studies 16(6): 2013, 712-729.

Benedicto, Jorge. "Transições juvenis para a cidadania: uma análise empírica das identidades cidadãs" in José M. Pais, René Bendit e Vítor S. Ferreira (Org.) Jovens e rumos, Imprensa de Ciências Sociais: Lisboa, 2011, pp. 353-372.

Bennett, A. Youth and Play: Identity, Politics and Lifestyle. In. J. Wyn and H. Cahill (eds.), Handbook of Children and Youth Studies. New York: Springer, 2015. 775-788.

Bennett A. and Kahn-Harris, K. (eds.) After Subculture: Critical Studies in Contemporary Youth Culture. Basingstoke: Palgrave MacMillan. 2004.

Bennett, W Lance and Segerberg, Alexandra. Digital media and the personalization of collective action: Social technology and the organization of protests against the global economic crisis. Information, Communication \& Society 14, 6, 2011, 770--799.

Boyd, A., \& Mitchell, D. O. (Eds.). Beautiful Trouble: A Toolbox for Revolution, 2012. https://doi.org/10.2307/j.ctt1bkm5nd

Burguess, J. Hearing Ordinary Voices: Cultural Studies, Vernacular Creativity and Digital Storytelling, Continuum. Journal of Media \& Cultural Studies 20(2), 2006, 201-214.

Burgess, J. and Green, J. YouTube. Online Video and Participatory Culture. Cambridge: Polity, 2009.

Buser, M., Bonura, C., Fannin, M. and Boyer, K. Cultural activism and the politics of place-making. City 17(5), 2013, 606-627.

Campos, R. Graffiti, visual culture and ethnicity: the black neighbourhood of Kova da Moura. In R. Martins and M. Canevacci (eds.), Lusophone Hip-Hop. Who We Are and Where We Are: Identities, Urban Culture and Belonging. Oxford: Sean Kingston Publishing, 2018a, 41-60. 
Campos, Ricardo. The Crisis on the Wall. Political Muralism and Street Art in Lisbon. In I. David (ed.), Crisis, Austerity and Transformation. How Disciplinary Neoliberalism is Changing Portugal. London: Lexington Books, 2018b, 109-130.

Campos, Ricardo. "O direito à voz no espaço público. Uma reflexão em torno das formas de apropriação do juvenil dos territórios urbanos”, in Rosana Martins, Maria Goretti Pedroso e Francico Cádima, Espaço público e direitos humanos: novos desafios, Rio de Janeiro: Editora Multifoco, 2011a, pp. 135-147

Campos, Ricardo. “Identidade, imagem e representação na metrópole.” In Campos, R; Brighenti, A. e Spinelli, L. (Org.) Uma cidade de Imagens. Produção e consumo visual na cidade, Lisboa, Mundos Sociais, 2011b, pp. 15-30 (ISBN 978-989-8536-03-7)

Campos, R., Nunes, P. and Simões, J. Protest rap and young Afro-descendants in Portugal. In J. Sardinha and R. Campos (eds.) Transglobal Sounds. Music, Identity and Migrant Descendants. New York: Bloomsbury Academic Publishing, 2016, 113-132.

Campos, Ricardo e Simões, José. “Jóvenes, medios digitales y participación política en Portugal” in José Sánchez, Eduard Ballesté e Carles Feixa (Org.) Política, movimientos sociales y juventud después de la primavera indignada, Lleida: Editorial Milenio, 2018, pp. 63-89

Campos, R., Simões, J. A. and Pereira, I. Digital media, representations and practices of recent activism in Portugal. Communications: The European Journal of Communication Research 43(4), 2018, 489-507.

Campos, Ricardo e Simões, José. "Digital participation at the margins: online circuits of rap music by Portuguese Afro-descendant youth", Young: Nordic Journal of Youth Research, 22 (1), 2014, 87-106 (ISSN 1103-3088) DOI: $10.1177 / 1103308813512931$

Campos, Ricardo; Vaz, Cláudia. "O rap e o graffiti como dispositivos de reflexão identitária de jovens afrodescendentes em Portugal.", Sociedade e Cultura, Vol.16, nำ1, 2013, 127-139 [ISSN (versão eletrônica): 1980-8194 / ISSN (versão impressa): 1415-8566] http://www.revistas.ufg.br/index.php/fchf/ article/view/28216/16061

Carmo, Renato e Simões, José (orgs.). Protest, Youth and Precariousness. Oxford: Berghahn Books, 2020.

Castells, M. Materials for an exploratory theory of the network society. The British Journal of Sociology, 51(1), 2000, 5-24. https://doi.org/10.1111/ j.1468-4446.2000.00005.x 
Castells, M. La société en réseaux. Paris: Fayard, 2001.

Delgado, Manuel. "Artivismo y pospolítica. Sobre la estetización de las luchas sociales en contextos urbanos", Quaderns-e, Institut Català d'Antropologia, Número 18 (2), 2013, pp. 68-80.

Di Giovanni, Julia Ruiz. "Artes de abrir espaço. Apontamentos para a análise de práticas em trânsito entre arte e ativismo", Cadernos de Arte e Antropologia, Vol.4, No2, 2015, pp.13-27.

McKay, G. DIY culture: Notes towards an intro. In G. McKay (ed.), DIY Culture: Party and Protest in Nineties Britain (pp. 2-43). London: Verso, 1998.

Mourão, Rui. "Performances artivistas: incorporação duma estética de dissensão numa ética de resistência", Cadernos de Arte e Antropologia, Vol.4, №2, 2015, pp.53-69.

Farthing, R. The politics of youthful antipolitics: representing the 'issue' of youth participation in politics. Journal of Youth Studies 13(2), 2010, 181-195.

Feixa, Carles. De jóvenes, bandas y tribus. Barcelona: Ariel, 2006

Feixa, Carles. A cidade secreta: os espaços quotidianos dos jovens, Trajectos Revista de Comunicação, Cultura e Educação, nº 3, p. 125-140, 2003

Feixa, Carles; PORZIO, Laura. Um percurso visual pelas tribos urbanas de Barcelona. In: PAIS, José M.; CARVALHO Clara; GUSMÃO Neusa M. (Org.) O Visual e o Quotidiano, org. Lisboa: ICS, 2008, p. 87-113

Feixa, Carles e Jordi Nofre (Eds.). \#Generación Indignada: Topías y utopias del 15M. Lleida: Editorial Milenio, 2013.

Feixa, C., Pereira, I. and Juris. J. Global citizenship and the 'New, New' social movements: Iberian connections. Young 17(4), 2009, 421-442.

Fischer, G. and Vassen, F. Collective Creativity: Traditional Patterns and New Paradigms. In G. Fischer and F. Vassen (eds.), Collective Creativity. Collaborative Work in the Sciences, Literature and the Arts. Amsterdam: Rodopi, 2011.

Florida, R. The Rise Of The Creative Class: And How It's Transforming Work, Leisure, Community And Everyday Life. New York: Basic Books, 2002.

Folio, J.-P. Au-delà de l'art: Créativité et expérience esthésique. Gérontologie et Société, 34(137), 2011, 37-48. https://doi.org/doi:10.3917/ gs.137.0037

Fradique, Teresa. Fixar o movimento - Representações da música rap em Portugal, Lisboa, Publicações Dom Quixote, 2003. 
Garcia-Albacete, G. M. Young People's Political Participation in Western Europe Continuity or Generational Change? Basingstoke: Palgrave Macmillan, 2014.

Guilford, J. P. Creativity. American Psychologist, 5(9), 1950, 444-454. https:// doi.org/10.1037/h0063487

Giroux, H. Youth in Revolt: Reclaiming a Democratic Future. New York: Routledge, 2016.

Guerra, P. Raw Power: Punk, DIY and Underground Cultures as Spaces of Resistance in Contemporary Portugal. Cultural Sociology, 12(2), 2018, 241-259.

Hall, S. and Jefferson, T. (eds.) Resistance through rituals: youth cultures in post-War Britain. London: Hutchinson, 1976.

$\mathrm{H}$ allam, E., \& Ingold, T. Creativity and cultural improvisation. (Associatio). New York: Berg Publishers, 2007.

Hankins, K. Creative democracy and the quiet politics of the everyday. Urban Geography 38(4), 2017, 502-506.

Hargreaves, I. and Hartley, J. The Creative Citizen Unbound. How Social Media and DIY Culture Contribute to Democracy, Communities and the Creative Economy. Bristol: Policy Press, 2016.

Harris, A. Transitions, Cultures, and Citizenship: Interrogating and Integrating Youth Studies in New Times. In D. Woodman and A. Bennett (eds.), Youth Cultures, Transitions, and Generations. Bridging the Gap in Youth Research. Basingstoke: Palgrave Macmillan, 2015, 84-98.

Harris A., Wyn J. and Jones S. Beyond apathetic or activist youth: 'Ordinary' young people and contemporary forms of participation. Young 18(9), 2010, 9-32.

Hart, M. Humour and Social Protest: An Introduction. International Review of Social History 52, 2007, 1-20.

Hebdige, D. Subculture: The Meaning of Style. London, Methuen, 1976.

Isin, E. F. Performative Citizenship. In A. Shachar, R. Bauböck, I. Bloemraad and M. Vink (eds.), The Oxford Handbook of Citizenship. Oxford: Oxford University Press, 2017, 500-523.

Isin, E. F. Theorizing acts of citizenship. In E. F. Isin and G. M. Nielsen (eds.) Acts of Citizenship. London: Zed Books, 2008, 13-43.

Isin E. F. and Nielsen, G. M. (eds.) Acts of Citizenship. London: Zed Books, 2008. 
Isin, E. F. and Turner, B. S. Citizenship Studies: An Introduction. In E. F. Isin and B. S. Turner (eds.) Handbook of Citizenship Studies. London: Sage, 2002.

Jeffrey, C. Geographies of children and youth II: Global youth agency. Progress in Human Geography 36(2), 2012, 245-253.

Jenkins, H. Fans, Bloggers, and Gamers: Exploring Participatory Culture. New York: New York University Press, 2006.

Juris, J. Embodying Protest: Culture and Performance within Social Movements. In B. Baumgarten, P. Daphi, and P. Ullrich (eds.), Conceptualizing Culture in Social Movement Research. Basingstoke: Palgrave Macmillan, 2015, 82-104.

Kahne, J., Middaugh, E. and Allen D. Youth, new media, and the rise of participatory politics. In D. Allen and J. S. Light (eds.), From Voice to Influence: Understanding digital citizenship in a digital age. Chicago: The University of Chicago Press, 2015, 35-55.

Kennelly, J. Citizen Youth: Culture, Activism, and Agency in a Neoliberal Era. Basingstoke: Palgrave Macmillan, 2011..

La Chapelle, J. Creativity Research: Its Sociological and Educational Limitations. Studies in Art Education, 24(2), 1983, 131-139.

Lack, J. Why are we "artists"? 100 World Art Manifestos. UK: Penguin Random House UK, 2017.

Landry, C.. The Creative City: A Toolkit for Urban Innovators. London: Earthscan, 2012.

Landry, C., \& Bianchini, F. The Creative City. London: DEMOS, 1995.

Lazar, S. and Nuijten, M Citizenship, the self, and political agency. Critique of Anthropology 33(1), 2013, 3-7.

Lévy, Pierre. Inteligência coletiva. Para uma antropologia do ciberespaço 5a ed. [S.l.]: Loyola, 2007.

Loader, B. D., Vromen, A., and Xenos, M. A. The networked young citizen: Social media, political participation and civic engagement. Information, Communication \& Society 17(2), 2014, 143-150.

Menezes, Isabel. "Da (inter)acção como alma da política: para uma crítica da retórica "participatória" nos discursos sobre jovens”, in José M. Pais, René Bendit e Vítor S. Ferreira (Org.) Jovens e rumos, Imprensa de Ciências Sociais: Lisboa, 2011, pp. 333-354

Molnár, V. Reframing Public Space Through Digital Mobilization: Flash Mobs and Contemporary Urban Youth Culture, Space and Culture , 17(1), 2014, 43-58. 
Moral, Jésus Sanz. "A participação política dos jovens portugueses: integração, participação, representatividade e legitimidade institucional" in José M. Pais, René Bendit e Vítor S. Ferreira (Org.) Jovens e rumos, Imprensa de Ciências Sociais: Lisboa, 2011, pp. 373-394

Mould, O. Urban Subversion and the Creative City. London \& New York: Routledge, 2015.

Muggleton, D. and Weinzierl, R. (eds.) The Post-Subcultures Reader. New York: Berg, 2003.

Pais, José Machado. Jovens e cidadania. Sociologia, Problemas e Práticas, $\mathrm{n}^{\mathrm{o}}$ 49, 2005, p. 53-70.

Pais, José Machado. Culturas Juvenis. Lisboa: IN-CM, 1993.

Paulus, P. B. and Nijstad, B. A. Group Creativity. An Introduction. In P. B. Paulus and B. A. Nijstad (eds.), Group Creativity: Innovation through Collaboration. Oxford New York: University Press, 2003, 3-14.

Pickard, Sarah and Bessant, Judith. Introduction. In S. Pickard and J. Bessant (eds.) Young People Re-Generating Politics in Times of Crises. Basingstoke: Palgrave Macmillan, 2018.

Pitti, I. Youth and Unconventional Political Engagement, Basingstoke: Palgrave Macmillan, 2018.

Recuero, Raquel da Cunha. "Comunidades virtuais - Uma abordagem teórica" Biblioteca Online de Ciências da Comunicação, 2004. (http://www.bocc. ubi.pt/pag/recuero-raquel-comunidades-virtuais.pdf)

Sánchez, J., Ballesté, E. and Feixa, C. (eds.) Política, movimientos sociales y juventud después de la primavera indignada. Lleida: Editorial Milenio, 2018.

Sandoval C. and Latorre G. Chicana/o Artivism: Judy Baca's Digital Work with Youth of Color. In A. Everett (ed.), Learning Race and Ethnicity: Youth and Digital Media. Cambridge, MA: The MIT Press, 2008, 81-108.

Sawyer, R. K. Group Creativity: Music, Theater, Collaboration. London: Psychology Press, 2003.

Sawyer, R. K. and DeZutter, S. Distributed Creativity: How Collective Creations Emerge from Collaboration. Psychology of Aesthetics, Creativity, and the Arts 3(2), 2009, 81-92.

Schacter, R. The ugly truth: Street Art, Graffiti and the Creative City. Art \& the Public Sphere. 3 (2): 161-176Simões, José Alberto (2010), Entre a rua e a internet. Um estudo sobre o hip-hop português. Lisboa: Imprensa de Ciências Sociais, 2014. 
Simões, J. and Campos, R. Digital Media, Youth and the New Grammars of Activism in Portugal. In R. Carmo and J. Simões (orgs.) Protest, Youth and Precariousness. Oxford: Berghahn Books, 2020.

Simões, J. A. and Campos, R. Digital Media, Subcultural Activity and Youth Participation: The cases of protest rap and graffiti in Portugal. Journal of Youth Studies 20(1), 2017, 16-31.

Simões, J. A., Campos, R., Pereira, I. and Esteves, M. Digital Activism, Political Participation and Social Movements in Times of Crisis. In I. David (ed.) Crisis, Austerity, and Transformation How Disciplinary Neoliberalism Is Changing Portugal. London, Lexington Books, 2018, 71-90.

Sloam, J. and Henn, M. Youthquake. The Rise of Young Cosmopolitans in Britain. Basington: Palgrave Studies in Young People and Politics, 2019.

Soep, E. Participatory Politics. Next-Generation Tactics to Remake Public Spheres. Cambridge, Mass.: MIT Press, 2014.

Staeheli, L. A., Attoh K. and Mitchell, D. Contested Engagements: Youth and the Politics of Citizenship. Space and Polity 17(1), 2013, 88-105

Stolle, D. and Hooghe, M. Shifting Inequalities? Patterns of Exclusion and Inclusion in Emerging Forms of Political Participation. European Societies 13(1), 2011, 119-142.

Street, John; Inthorn, Sanna e Scott, Martin. From entertainment to citizenship. Machester: Manchester University Press, 2013.

Van Dijk, Jan. "The reality of virtual communities" in Jo Groebel (ed.) Trends in Communication I. Amsterdam: Boom Publishers, 1997, pp. 39-63.

Vandegrift, D. Youth Political Subjectivity in the Global South: Crossing Conceptual Boundaries in Less Examined Contexts. In D. Woodman and A. Bennett (eds.), Youth Cultures, Transitions, and Generations. Bridging the Gap in Youth Research. Basingstoke: Palgrave Macmillan, 2015, 142-156.

Vergara, Camile. “Corpo transgressão: a violência traduzida nas performances do Coletivo Coiote, Bloco Livre Reciclato e Black Blocs", Cadernos de Arte e Antropologia, Vol. 4, No 2 |-1, 2015, 105-123.

Willis, P. Commom Culture: Simbolic Work at Play in Everyday Cultures of the Young. Milton Keynes, Open University Press, 1990.

White, M. Can an Act of Citizenship Be Creative? In E. F. Isin and G. M. Nielsen (eds.) Acts of Citizenship. London: Zed Books, 2008, 44-56.

Yanik, L. "Humor as Resistance? A Very Short Analysis of the Gezi Park Protest Graffiti". In Toktamış, K. and David, I. (eds.), Everywhere Taksim: the Gezi 
Spirit and the New Dynamics in Turkish Politics. Amsterdam: University of Amsterdam Press, 2015, 153-184.

Zaimakis, Yiannis. 'Welcome to the civilization of fear': on political graffiti heterotopias in Greece in times of crisis". Visual Communication 14 (4), 2015, 373-396

Recebido em 09/04/2020

Aprovado em 01/06/2020 
